\title{
Developing Opportunities of the Indonesian Navy Civil Servants through Career Pattern as a World Class
}

\author{
Bureaucrat
}

\section{(Evaluation of Development Career Patterns Policy of the Indonesian Navy Civil Servants as a Respond to the Change of Human Resource Management)}

\author{
Acep Maksum \\ Students of the Post Graduate Program, Management Science Program \\ Human Resource Management, State University of Jakarta \\ E-mail: acep.maksum@gmail.com
}

Hady Efendy (Corresponding Author)

Education Practice and Academic Consultant

E-mail: efendy_hady@yahoo.co.id

Received: Sep. 12, 2017 Accepted: Sep. 29, $2017 \quad$ Online published: Oct. 16, 2017

doi:10.5296/ijhrs.v7i4.11836

URL: https://doi.org/10.5296/ ijhrs.v7i4.11836

\begin{abstract}
In this paper, a review of five published scientific journals was conducted and an evaluation of the career policy of the Indonesian naval civil servants based on the study of the journal. To be able to create The Indonesian Navy Civil Servant (Navy Civilian) career development system, need to design a pattern of career employees in accordance with the organization's mission, culture and conditions of supporting device of employment system which is still valid to the organization, according with the mandate of law number 5 year of 2014 concerning to the state civil apparatus. Developing career of navy civilian system essentially a systemic effort, which includes the structuresand processes planned that produce to meet employee competencies and organizational needs. The implementation in the organization of the Indonesian Navy for career development of civil servants is not equivalence with the governmental organization in
\end{abstract}


general, stalled at a certain limit, deadlocked and stagnates. The career pattern should be structured and measured to provide personnel devotion trip in reaching the retirement age, then there should be a review for navy civilian career pattern development to improve the management pattern of his career due to state civil apparatus as a profession, should give priority to the principles of professionalism, competence, qualifications, performance, transparency, objectivity based on management of human resources towards the realization of the government bureaucracy that is professional and able to compete.

Keywords: career pattern, human resources, navy, navy civilian, organizational policies

\section{Introduction}

In the Law of the Republic of Indonesia Number 43 year of 1999 on the fundamentals of civil servant, in chapter I point 8, state clearly that the management of civil servants (Pegawai Negeri Sipil/PNS) is the overall effort to improve efficiency, effectiveness and the degree of professionalism of the implementation of tasks, functions and responsibilities of personnel, including planning, procurement, quality development, placement, promotion, remuneration, welfare and dismissal. In essence, the personnel management mostly oriented to Human Resources professionalism (HR) of its personnel (PNS), which will provide services to the public in an honest, fair, and equitable in the administration of state duty, governance and development, not partisan and neutral, out of all the influence groups and political parties, and does not discriminate in providing services to the public. In order to implement the service, human resource (PNS) are required to have professionalism and a global perspective and has high competence in the context of public bureaucracy.

To ensure the implementation of the government's duty and be effective and efficient development of the civil servants needed guidance system capable of providing a balance between ensuring the rights and obligations, with a mission that every unit of government organizations should be able to motivate the performance of civil servants. One of the efforts that included part of the developing system is the preparation of a career pattern that allows the potential PNS to be developed as optimal as possible in order to achieve organizational goals more effectively. PNS career developing system should be structured in such a way that the creation of objective conditions which can boost the achievements of civil servants. This can be possible if the placement of civil servants is based on harmony between the work requirements with the performance of its civil servants.

From several concepts of the Personnel Formation List (Daftar Susunan Personel/DSP)/ Organizational Personnel Table (Tabel Organisasi Personel/ TOP) in the organization of the Indonesian Navy, in all levels of the organization, still indicates a frame and construction guidance that has not been directed, for example, that some DSP have not yet provided the opportunity of structural positions for civilian up to class office V or Echelon III, which means that the DSP civilianis still schemed in the highest stage particularly in level of class rank III/d and some classes of rank IV/a and a few number IV/b, thus class rank on top of that there is no pattern advanced careers, yet even this condition in terms of educational background and competence. In other words that the system of career development or opportunities to work effectively within the organization to meet future complete or stalled at a certain limit (assuming 
that the organization navy career development of civil servants is not equivalence with the governmental organization in general, it is necessary to review the intake of civil servants, the level education and class rank are required for the organization of the Indonesian Navy).

Indeed, a good career developing system does not recognize the deadlocked and stagnant, career patterns should be structured and measured to give devotion trip someone up in reaching the limit of retirement age. Based on the Law of the Republic of Indonesia Number 8 Year of 1974, Law of the Republic of Indonesia Number 43 Year 1999 concerning the principles of human resources, explained that the civil servant is every citizen of the Republic of Indonesia that has been qualified specifically, appointed by the competent authority and entrusted with domestic tasks in an office, or entrusted with the task of other countries, and are paid based on the valid legislation.

Stagnation of civil servants career in certain strata in the organization of the navy, strongly felt and cause restlessness that resulted in poor performance, works without the spirit, the decline of confidence and a weakening job performance. It should be a serious discussion because the civil servants who are employed and play important roles in the functions of administrative services, health services, and more technical functions would impact and get potential affect to the operation readiness of the Indonesian Navy.

Various causes of the stagnation of career civil servants in the navy must immediately find a way out and the remedies constructive approaches and methods, and more particularly is to understand the nature and direction of development of civil servants in general in accordance with Law No. 5 of 2014 on Civil State Apparatus (Aparatur Sipil Negara/ASN)'s Law different from the previous law governing the civil servant. In this study will be conducted analysis of five research results that have been published in the form of scientific journals related to the title of the study. The results of the review will be analyzed and evaluated against the policies applicable to the Indonesian Navy Civil Servants.

\subsection{Problems Formulation}

The problems of this paper are:

a. Capturing the pattern of career developing by military/navy organizational culture based management?

b. Inventarisation problems of civilian navy career pattern, especially by the changing of human resource management?

c. What is the meaning ofcareer stagnation of in navy civilian?

d. What are the strategies used to overcome the problems of career stagnation of navy civilian?

\subsection{Benefit of Writing}

The benefits that can be taken in this paper, related to career development pattern of navy civilian are:

a. To find out more about mapping career development pattern of navy civilian career and problems those occur. 
b. To know the strategies that can be used to overcome the problems of career stagnation of navy civilian.

c. As an input in strcturing policy of corporate governance and compliance with civil service norms, standards, and conformity in accordance with applicable regulations.

\subsection{Methodology}

In accordance with the problems and objectives proposed in this study is to obtain a general description of discovering the renewal of innovation, strategic factors, efforts undertaken, relevance to policy in military organization, and applications on the improvement of career system from five articles which is published by five different international journal. This research is a research based on qualitative approach with content analysis method by using inductive procedure. The purpose of content analysis is to find the depth of meaning that exists in the object under study. So this study will present a report containing data citations to describe the innovation of an organization's career management, strategic factors that support career management, the efforts undertaken for the development of career and applying it in human resource development efforts.

\section{Assessment Analysis (A Related Journal Analyzed)}

a. Edgar H Schein. (2015). Corporate Culture, MIT Sloan School of Management, Cambridge, MA, USA. (C) 2015 Elsevier Ltd. All rights reserved.

This research was conducted by Edgar $\mathrm{H}$ Schein, from the MIT Sloan School Of Management, Cambridge, MA, USA, discuss the extent to which corporate culture with regard to economic performance are briefly reviewed and the concept of cultural creation and change, direction of evolution into a cultural force, the view point toward the establishment or change of culture, research purpose; discusses the process of cultural change in relation to the performance of the organization in accordance with the character selection/organizational behavior. Research methodology; 1) The previous organizational culture profile; 2) Creating the appropriate organizational culture typology conception; and 3) Clinical or ethnographic description that highlights the unique cultural aspects. Weaknesses/Excess; weakness is only discussed through theoretical approach, has not been accompanied instance in a study in an organization. Relevance/applications with human resource development; The results of this study can be used as a basic theory in the study of human resource development aspect of cultural change that already exists in an organization that is converted into an organizational culture that is much better and respond to a changing demands. In this paper, the research results can be used as a reference related to the assignment of civil servants in an organization with a strong military organization (organization of the navy).

b. Yoram Koren, Xi Gu, \& Theodor Freiheit. (2016). The Impact of Corporate Culture on Manufacturing system design, University Of Michigan, Ann Arbor, MI, USA, Elsevier Ltd. All rights reserved.

This research was conducted by Yoram Koren, $\mathrm{Xi} \mathrm{Gu}$, \& Theodor Freiheit, from the University of Michigan, Ann Arbor, MI, USA, discusses the testing of two models of production system typical in the automotive that is serial lines in parallel and RMS by means 
of a cross (RMS with Crossovers) associated with organizational culture, this is done with a reason why the practice of design configurations Japanese factories different from the system configuration in the US factories. Objective; to compare and determine which the series production machine is best suited to the characteristics of the work culture in the Japanese and American automotive companies, especially related to the prevailing culture in each country. Research Methods; Perform mathematical calculations on two types of engine configurations associated with the production of two cultural characteristics of the work (Japanese and American). Weaknesses/excess; discussion only on mathematical calculations related to the kinds and types of production system configurations of machines to determine which configuration is more effective but on the other hand the title of the paper is emphasized on the impact of organizational culture. Related to the system configuration which is more purple was not explained (if used in Japan or in America) just summed up the advantages and drawback without any discussion with the correlation of the corporate culture in Japan and in the United States. Relevance/applications with the improvement of human resource development; The results of this study can be used as the basis of the theory that the culture of a country/organization will greatly affect to the working system in the organization, adjusted to the type/kind of job.

c. Brad McLennan, Peter Mc. Ilveen, \& N Harsha Perera. (2017). Pre-service Teachers' Self-Efficacy Mediates The Relationship Between Career Adaptability And Career Optimism. School Of Teaching \& early Childhood, University of Southern Queensland, Toowoomba, Australia. Elsevier Ltd. All rights reserved.

This research was conducted by Brad McLennan, Peter Mc. Ilveen, \& Harsha N Perera, from the School of Teaching \& Childhood, University of Southern Queensland, Toowoomba, Australia, discusses the extent to which self-efficacy influences of pre-service and the other psychological factors associated with career involvement. This study contributes to the understanding of complex linkages to show that pre-service workers' self-efficacy directly predict their careers optimism and mediates the effect of adaptability with optimism career. Research purposes; to predict/determine the relationship or influence adaptation of pre-service career against optimism career, or to find out "What career enhancement adaptability associated with increased self-efficacy?". Research Methods; the method used is the collection and analysis of quantitative data derived from the questionnaire measures of the participants, the 'self-ratings of self-efficacy, career adaptation, and career optimism. Analyzed through structure calculation model with a standard estimate (structural model with standardized estimates). Weakness/excess; discussion about the approach theoretically only, not showing the approach and calculation results of questionnaires with a few examples of the questions in the questionnaires as well as a clear methodology for the calculation basis on questionnaires used. Relevance/applications with human resource development; The results of this study can be used as the basis of further research related to the degree of influence between intra-personal abilities, careers optimism and advancement opportunities of an employee/worker.

d. Peter A. Creed, Michelle Hood, \& Shi Hu. (2016). Personal Orientation Career As An antecedent To Stress and Employability Confidence: The Roles of Intervening Career 
Goal-Performance Discrepancy and Career Goal Importance. School of Applied Psychology and Menzies Health Institute Queensland Australia.

This research was conducted by Peter AC reed, Michelle Hood, \& Shi Hu, from School Of Applied Psychology And Menzies Health Institute Queensland Australia, discusses the mechanisms underlying and connecting the personal orientation for the results of behavioral and affective. Identify and understand the underlying mechanisms/encourage behavior careers, related to two aspects related to the career (career distress and employability confidence) that affect to the future career. Research purposes; to predict/determine or influence the relationship between the individual career objectives, proactive orientation, difficult ies of career development and confidence of positive performance. Research Methods; the method used is a survey of/involved 564 respondents were enrolled in various types of education (first half) were then interviewed. Furthermore, the results were analyzed through calculations of the team to measure the correlation between career goal, performance discrepancy and well-being. Weaknesses/excess; the discussion has not clearly display the calculation results of questionnaires with a few examples of the questions in the questionnaires as well as a clear methodology for the calculation basis on questionnaires used. Relevance/applications with human resource development; the results of this study can be used as a basis for understanding the underlying mechanisms/encourage behavior careers, related to two aspects related to the career (career distress and employability confidence) that affect the future of personal career.

e. Victor Dobbin. (2017). Ethics and the Military Community. The Leadership and Ethics Centre, Northern Ireland. Journal of Defense Resources Management. No.1/(1). Pp. 69-76.

This research was conducted by the Victor Dobbin from Defense Resources Management Northern Ireland, discusses the training program for the military leadership in the application of ethics training. Training for the military leadership in the development of high moral standards. Research purposes; to evaluate ethics program as the basis for revision of the code from time to time and gain a valuable understanding of sharing and comparing with other military training program. Research methods; studying the events of military ethics violations in various countries for further discussed with some approach to theories of ethics military environment. Weaknesses/excess; the discussion was limited to the facts of violation of military ethics associated with theory of self-assessment, leadership, training and discussion as well as updates on current conditions. Relevance/applications with human resource development; the results of this study can be used as a basis of comparison with the approach of the norms and ethics among civil servants (non-military) in the military organization (the navy).

\section{Theoretical Basic}

\subsection{Basic Theory of Civil Servant}

Some of the theoretical basis that can be used in the discussion of developing opportunities of the Indonesian Navy Civil Servant through career pattern as a world class bureaucrat (evaluation of development career patterns policy of the Indonesian Navy Civil Servants as 


\section{Macrothink}

responding to the change of Human Resource Management), that is:

a. Definition of Public Policy.

Some definitions of public policy (which discussabout the policy in the Indonesian Navy), among others (Rian Nugroho, 2013: 3). Harold Lasswell \& Abraham Kaplan (1970.71), defined as a program that is projected with a variety of objectives, values and practices of a particular (a projected program of goals, values and practices). David Easton (1975.212), defined as a result of government activity (the impact of government activity). Carl I. Friedrick (1963.79), defined as someone proposed a series of actions, group or government in a certain environment, with the threats and opportunities, where the proposed policies are intended to harness the potential and overcome the existing obstacles in order to achieve specific purpose.

b. Policy Research.

Research policy is research relating to formulation and policy formulation, policy implementation, policy performance, and environmental policy (Rian Nugroho, 2013: 45). Research on policy formulation is the core of legal research. The following diagram is an overview of the policy research activities:

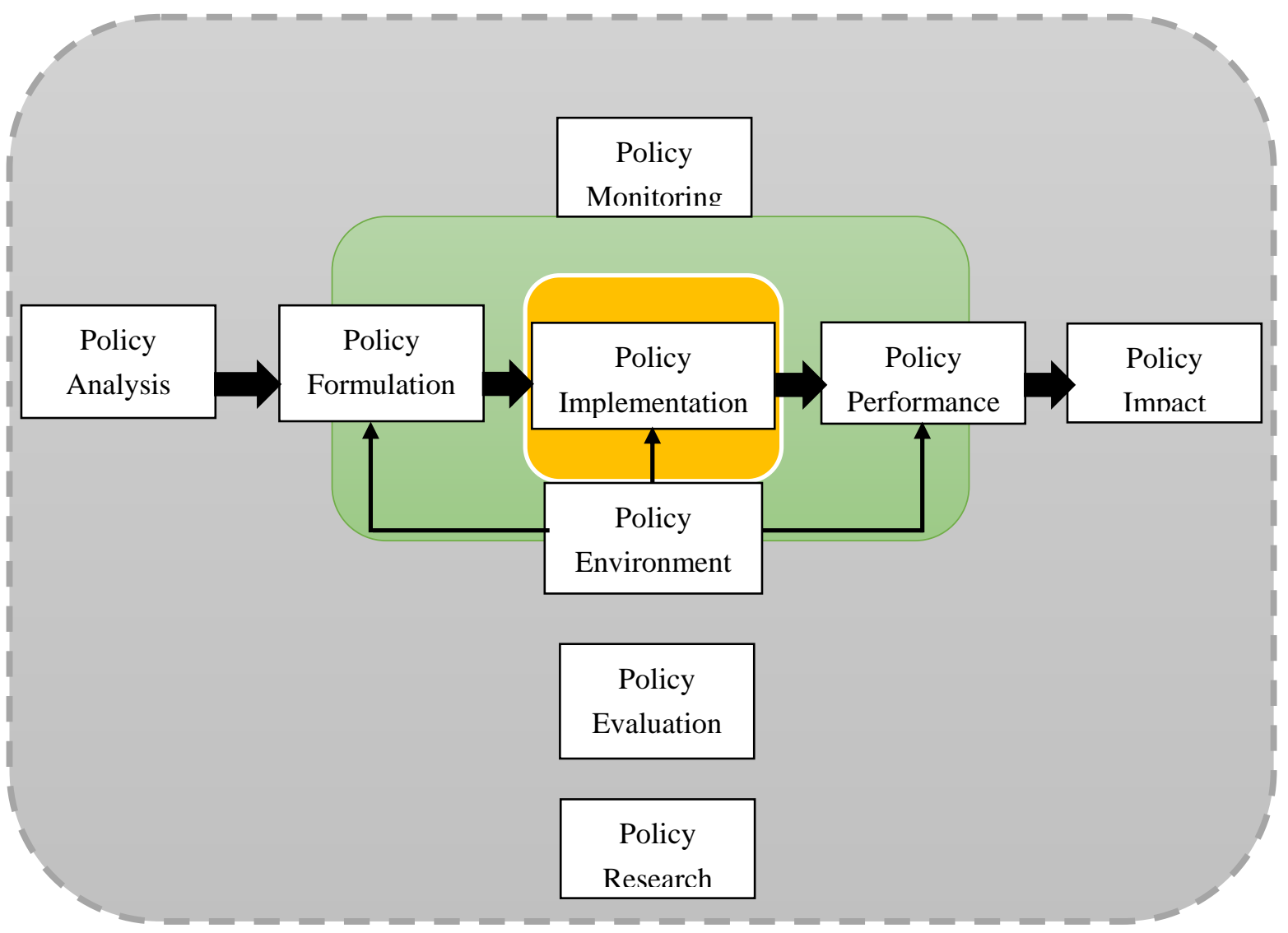

Figure 1. Policy research activities

c. Policy Evaluation.

A policy is a master plan drawn up by the government in serving the needs of community members. Policy is operationalized in the form of law, government regulation, presidential 


\section{Macrothink}

International Journal of Human Resource Studies

ISSN 2162-3058

2017, Vol. 7, No. 4

regulation, and ministry regulation, in TNI environment it will be breakdown u pto the chief of army staff regulations. Every policy must be evaluated to determine whether the beneficial policies, can achieve its objectives, implemented efficiently, and implementing accountability. Other terms are often confused by the common people is policy analysis. Policy analysis is to determine or choose an alternative policy the best of a number of alternative policy. While the policy evaluation is to measure the value and benefits of policies that are being or have been implemented.

In the implementation, policy evaluation can be used as feedback for program activities, as shown in the following figure 2 :

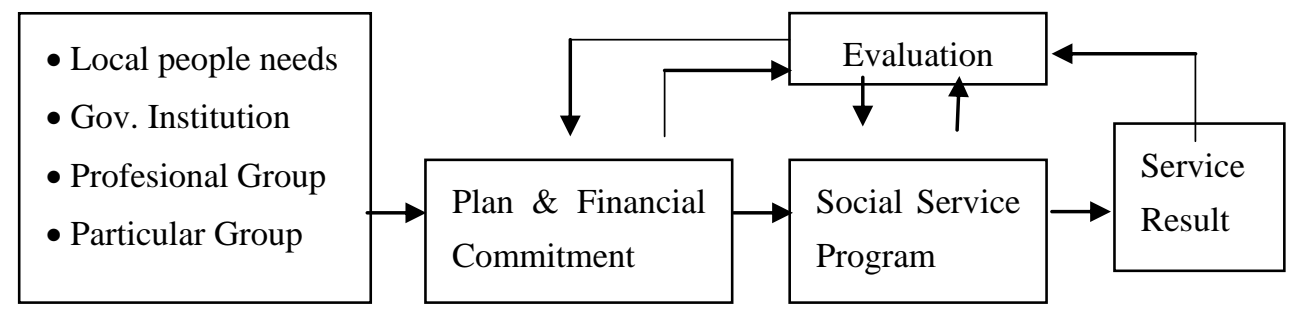

Figure 2. Position evaluation as a feedback (Posavac \& Carey, 2007)

Furthermore, it can also use the policy analysis method with the problem approach, as shown in the following figure (William N Dunn, 20013: 21):

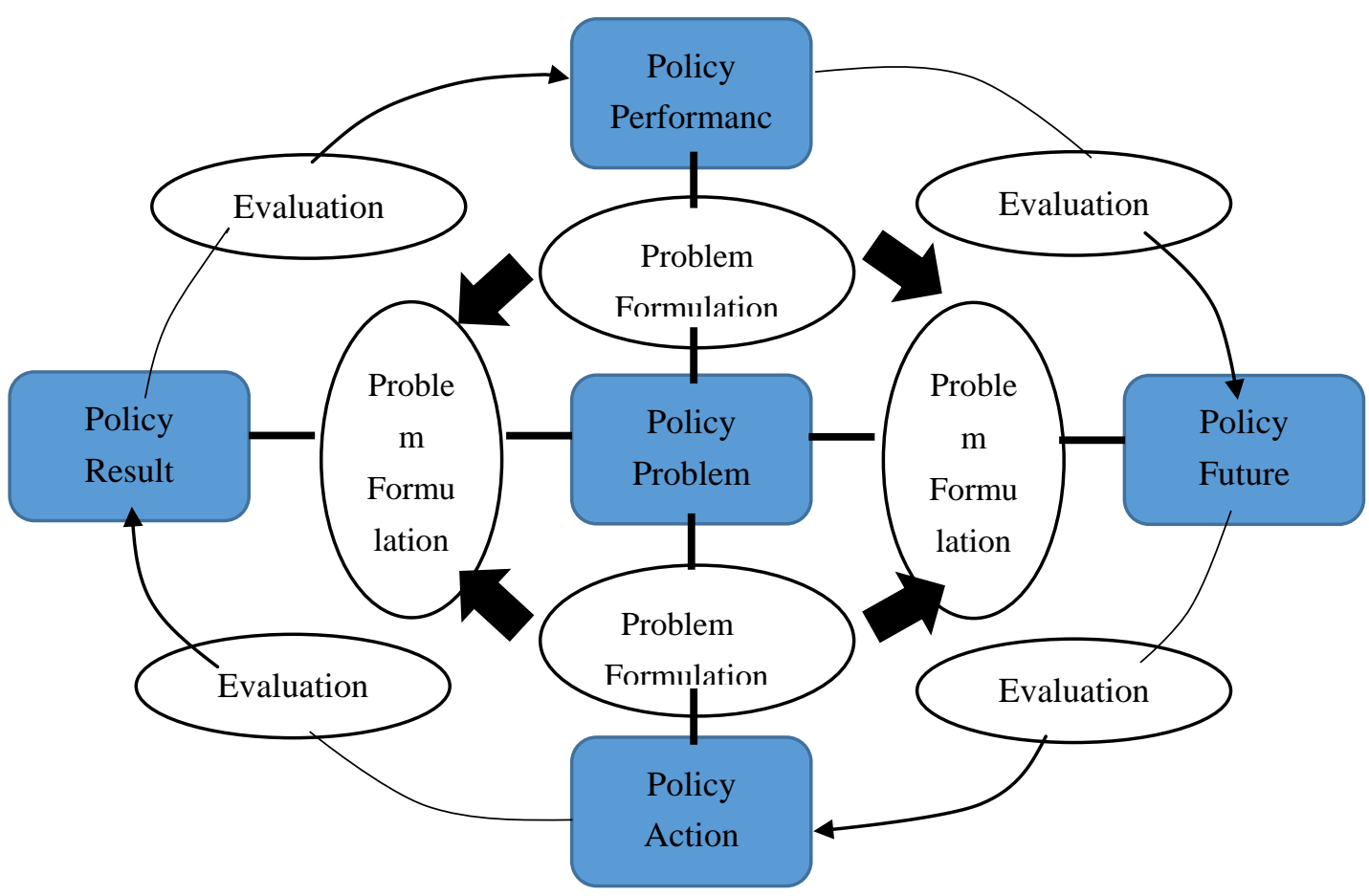

Figure 3. Analysis of problem-oriented policies

d. How the manager make changes. 
As a follow up of the implementation of the evaluation on career development policy, of course there will be the possibility of a change of policy which is currently implemented. If will be a change, of course, a manager / leader must know the stages in the implementation of these changes (change management). There are several things to consider in managing change (Winardi, J., 2015: 95), namely:

1) Some objectives of the planned changes. Changes planned strived to achieve two general types of results (Cook et al., 1997: 539-540).

The first type, directed toward improving the ability of the organization concerned, in order to cope with the changes that are not planned, that is encountered him.

The second type, the planned changes directed towards efforts to change the behavior of employees so that they become more effective contributors to the organization's objectives.

2) Performance gaps between the conditions prevailing at this time with future/desired condition. In this context it is a condition of career civil servants to be more open to achieve optimal accomplishment.

3) The agents of change are individuals or groups who are given the responsibility to change behavior and systems. In this context, agents of change ranging from leaders who are authorized to change the regulations, up to the individual to be willing to change to reflect the policy change.

4) Targets and the process of change. It includes humans, culture and management.

e. Career development and the role of employees in career development.

We can define career as a position held by a person's job for years. Career management is a process that allows employees to becomedeeply understand and develop their career skills and interest effectively both within the company and after they left the company (Gary Dessler, 2015: 379). Career development is a series of lifetime activity (such as workshops) that contribute to the exploration, formation, success, and fulfillment of one's career (Gary Dessler, 2015: 380). Planning a career is a deliberate process so that one becomes aware of the skills, interests, knowledge, motivation, and other personal characteristics; get information about opportunities and choices; identify related career goals; and establish an action plan to achieve specific goals.

We will see that the manager of employees and employers should play a role in demanding and developing the careers of employees. However, employees must always accept full responsibility for the development of his career and his own career success.

Furthermore, employer and management have a role in demanding career employees, but no employee will hand over this task to others. Career planning means adjusting the strengths and weaknesses of individuals with job opportunities and threats. The person wanted to pursue jobs and careers that utilize interests, talents, values, and skills. He also wants to choose jobs and careers that match the projected future demand for various types of jobs. The consequences of a bad choice is too important to be left to others. There are so many resources that can be selected, as an example of career planning assistance, career counseling expert John Holland says that 
personality (includes values, motives, and needs) is one of the determinants of career choice. Thus, a person with a strong social orientation may be interested in careers that require interpersonal activity rather than intellectual or physical and into jobs such as social work. Holland found six basic personality types or orientation. Individuals can use the (Self-Directed Search-SDS), to assess the orientation of the job and the job of their choices.

\subsection{The Pattern of the Career Development of Civil Servants}

According to the Law of the Republic of Indonesia Number 5 year of 2014 concerning the State Civil Apparatus, it should be understood that there are several approaches to develop career of civil servants, among others:

a. Civil Servants Development Career System. It is essentially a systemic effort, which includes the planned structures and processes that produce harmony between employee competencies and organizational needs. The components in the guidance system includes:

1) Mission, objectives and organizational procedures that are common indicators of performance, the need for infrastructure and facilities including qualitative and quantitative needs of human resources.

2) Occupation Map, which is a reflection of the composition of positions vertically describe grouping types and specifications of duties within the organization.

3) Competency Standards, which is the level of skill the scope and terms of office that must be met to occupy a position in order to achieve objectives of the organization that became duties, rights, obligations and responsibilities of the rank positions.

4) Flow career, is a pattern of alternate path of development and progress of civil servants throughout his service in the organization, with the philosophy that career development should encourage the achievements of employees.

b. Civil Servant Career Path. Civil servant career path is a movement pattern service positions/civil servants either horizontally or vertically always lead to higher level positions. The definition Components are as follows:

1) Standard performance appraisal of civil servants, which is an instrument for measuring employee performance level compared to the competency positions standard that are and will be occupied by civil servants.

2) Navy civilian education and training, is an attempt to align the performance of employees or people outside the organization who would occupy a position with competence standards that have been set.

3) Succession plan is a plan mutation positions were prepared on the level of potential employees associated with a pattern position and competence standards, the succession plan is established by considering the estimated future organizational needs associated with employee planning and outcome assessment of the potential employee.

c. The career pattern of civil servant. The pattern of career civil servant is the development patterns of civil servants that describes the flow of career development that shows the relationship and harmony between the position, rank, education and training positions, competence and term of office of a civil servant since he was appointed first in office until the 
pension (Government Regulation No. 100 Year 2000 jo Government Regulation No. 13 of 2002). The meaning of government regulation are as follows:

1) Patterns of movement. The move from a structural position to functionally and from structural to functional positions either horizontally, vertically or diagonally as well as the displacement of the working area.

2) Switching positions horizontally is the transfer of positions at group level position/echelon and the same rank positions.

3) Switching positions vertically is the move that is promotion.

4) Switching positions is diagonally is the transfer of positions from a functional to a structural position and vice versa.

Furthermore, with reference to regulation legislation personnel existing career pattern for civil servants may be explained by the following stages:

1) Stage for recruitment, is an attempt to get employees out of the labor market through a selection based on job requirements.

2) Stages orientation, monitor their talents, interests and potential of civil servants.

3) Training patterns and development tasks.

4) Stabilization selectively profession:

a. As a structural officer in accordance with the managerial skills required.

b. Applying their expertise as a functional official.

5) Profession maturation stages selectively as follows:

a. For administrative positions, for those who have the ability to direct and determine policies in the field of their respective duties, in line with the organization's mission and direction of the wisdom of the leadership.

b. For the functional position that has the level of knowledge the ability to reason, assessing and solving problems scientifically.

Another factor related to the stagnation of career civil servants navy is the institution that is closely related to organizational culture, that there is still confusion about the function and authority of each working unit, so some working units further highlight the authority of the role in the implementation of the Organization function (characteristic of a military organization).

d. Institutional policy of the Indonesian Navy

In general, the navy policy, placing civil servants as a complement of a military organization, with a list of the relative positions as administrative personnel based on the duties and functions of the unit/organization or may be a position that is not a function of military command. At this time the structure/space positions for civil servants in the List of Personel Formation (DSP) is just only available in the level space class III and a little space at class IV, so if it is still possible that they could be given the policy to officiate on military positions (as a function of staff).

Referring to the prevailing regulations, good organization institutional policies associated with the careers of civil servants patterns can be set by these approaches: 
a. Determination career policy that sets the organization as a set of activities which has orientation to the mission and functions, instead of structure. The policy is based on consideration that the mission of the organization is relatively fixed even if the structure can be changed, whereas the approach followed by the organizational structure is relatively more vulnerable because it is always adapted to changes of strategy and organizational and environmental conditions as well.

b. Occupational approach is a specifications of organizational dimension based on expertise not to approach educational background, because this approach does not guarantee compliance. In fact that the dimensions of job competency standards and performance, can guarantee the implementation of the achievement of organizational goals. In other words, that the career patterns generally have one or more of the following objectives:

1) Can utilize any type of professional skills in accordance with needs of each organizational unit.

2) Optimizing utilization of human resources in every unit of the organization based on their competence and focus on every mission.

3) Build capacity, skills efficiently and rationally, so the potential, energy, talent and motivation objectively channeled toward the achievement of organizational goals.

4) With the clear and rigidspecification and responsibilities, rights and authority that have been distributed in a balanced manner on all organizational levels, being expected that every office holders can achieve maximum output.

5) With the career pattern, each employee will be noted their development for increasingpossible positions from the lowest to a higher level in an objectively and fair.

6) The basis for any leadership in the decision making process, related to the personnel management system.

7) Generate benefits and optimal working capacity.

Another important factor is the opportunity of self-development of civil servants who are not accommodated in a planned and sustainable so that civil servants should strive alone in improving his ability, because it was realized that the organization has not given the widest opportunity for developing a capability of civil servants other than just atraining programs the has been determined by the Ministry of Defense.

\subsection{The Spirit of Bureaucratic Reform}

The spirit of bureaucratic reform in accordance with Presidential Regulation No. 80 year of 2011 concerning the grand design Indonesia reforms bureaucracy from 2010 to 2025, requires all civil servants for having the competence as a reference to measure the performance of which a civil servant must have abilities through civil servant development opportunities. Many diagnostic performance dimensions that must be mastered by a civil servant, consists of:

a. Planning and Organizing. Ability to develop targeted by reality, assign tasks to subordinates and in using of resources and time.

b. Development of Decision. The ability to make decisions by looking at the external and internal development organization, confidently and timely. 
c. Delegation of powers/employment. The ability to share the workload and responsibilities evenly to subordinates and coordinate its implementation.

d. Analysis capabilities. Ability to approach the problem thoroughly, carefully and systematically.

e. Adjustment (Adaptation). Capability to understand and adjust the idea, procedures and issues.

f. Monitoring capabilities. Ability to supervise/control to create a productive work atmosphere.

g. Initiative. Ability to work without supervision and developing plans, methods and ideas.

h. Cooperation. The ability to work together in groups and synergy.

i. Communication/negotiation. The ability to convince others to negotiate and ability to write clearly and concisely.

j. Technical capability. Capability to understand the substance, info, techniques in performing the tasks.

k. Administration capabilities. Mastery of administrative policies, rules and regulations and the application fruitfully.

\subsection{Policies of Civil Servants Development in the Navy}

Fostering to the navy civilians have already done by regulations which apply both issued by the Ministry of Defense (Kemhan), Indonesian National Armed Forces (TNI), Indonesian Navy (TNI AL), as well as by the relevant agencies, namely the regulations issued by the Minister of State Apparatus Reform (PAN-RB), Head of the Civil Service Agency (BKN), and Chairman of the Institute of Public Administration (LAN). In the form of changing and adding to the moral attitudes of employees who are responsible for carrying out tasks in accordance with the demands of the organization.

Fostering to the navy civilians today compared to the previous past five years has significant progress, especially with the enactment of Government Regulation of the Republic of Indonesia Number 100 year of 2000, as amended by the government regulation of the Republic of Indonesia Number 13 Year of 2002 concerning the appointment of civil servants in structural positions. Although not yet fully implemented, yet quite bring meaningful change. With the enactment of government regulations will be hoped that navy civilians have the equal status, rights and obligations as well as civil servants who are posted in the other Ministry of Government. Thus, a civil servant in the navy are given equal opportunity to occupy a position in the organization as well as anothermilitary personnel. However, in fact there are still many aspects such as policies, organizational culture, equality that until now there has been no change, making it difficult for navy civilian to develop their career. So that tends to decrease the motivation, causing a lack of confidence, lack of achievement-oriented and declining discipline.

The existence of navy civilians in the organization have play an important role and determines the success of the organization. The existence of civil servants in the navy in particular is no longer as a supplement, but as a complement. Thus, it needs sustainable developmentto improve its performance and to play a role in taking responsibility according to the scope of 
their respective duties.

The success of an organization is determined by the appropriate manning. Therefore, an organization needs people who do their jobs well and properly. The need for professional personnel (have sufficient competence) is a must in answering the challenges to the implementation of the basic tasks and functions of an organization, especially Indonesian Navy in the recent and future againts the complexity. In achieving the desired organizational army/navy manned by civil servants and army personnel in the execution of duties and positions are partnerships, should be given the same opportunities, fair, and according to regulations so that the organization can be run in a balanced, harmonious, and mismatched. Personnel development should be carried out earnestly with all available regulations consequently and consistently.

Guidelines for the development of navy civilians that's assigned must refer to all laws that apply equally to civil servants in general, but still refers to the peculiarities of army/navy parallel to perform basic tasks and organizational functions, as well as promotion rights, obligations and opportunities are equal and fair for all personnel army/navy career training, education, welfare and awards. This is a necessity because of the level of accountability demands that the higher the complexity of the challenges faced in the implementation of basic tasks and functions of the TNI.

Based on the Decree of the Chief of Naval Staff Number Skep/933/VI/2006 dated June 28, 2006 concerning on Career pattern, Placement and Position of the Civil Service in the navy, in this case states that fostering navy civilians should always be intended to generate benefits as one force component of the defense.

\section{Analysis Result and Discussion}

\subsection{Condition of Navy Civilian Today}

Seeing the power composition of civil servant who was assigned in the TNI AL until February 2017 amounted to 8499 people (Space class I: 182 people, class II: 4,573, class III: 3,484 people and class IV: 260). Civilian as an integral part of development patterns personnel of the Navy as a whole, should have same proportion with military personnel, but the fact that development patterns of civilian (educational and career pattern) there is a specific difference, because there are rules in general of civilian which have relation to the ministry outside the organizational structure of the TNI (Ministry RB, BKN \& Kemhan).

Fostering of civilians should be responsive to technological developments by not forgetting the factor of cohesion and relevance to the environment. It should be done by including the active components to create a feeling partially responsible. Each member was given the opportunity (the right and opportunity) equal to education, positions and ranks in accordance with the loyalty, dedication and ability. Fostering of civilians requires that every leadershoould always be a model for all men and the environment in the dedication, attitude, behavior, knowledge and skills without ignoring seniority, based on the blend of career and achievement system. 
All the timethe development patterns of civilian is not systemic, it can be seen in determining the number of new procurement and determining the participants number of Service Examination (Ujian Dinas/Udin), Diploma Adjustment (Penyesuaian Ijasah/PI) and the Leadership Eduction and Training (Diklatpim) level III and IV. It is still limited by policies that are not written and not permanent, which should be based on the calculation according to the needs of the organization, so consequently there is accumulation at the level of Space class III/c, and class III/a exceeds existing DSP (III/c the real 837: DSP 442, and III/a real 971: DSP 38), then there are civilians who have certificatesof Diklatpim III/IV are not seated in the appropriate positions.

Although it has done a lot of changes in existing regulations, but not yet fully implemented, so do not bring a significant change. Until now there has been no change of policy both from the organizational culture, equality among employees and other aspects, making it difficult for civilian in the development of his career. This resulted in career development is not operating effectively, so that tends to decrease the motivation, causing a lack of confidence, lack of achievement-oriented and declining discipline. In addition, in the relationship between civilian and military, occurred inharmonious and treatment are different, thus lowering the performance.

The quality of the work of civil servants the navy tends to decrease resulting from a work environment that is less comfortable to work optimally and organizational climate were less open, causing dissatisfaction and fear for employees to express their interests, which in turn causes the target program of work that has been set is hard to achieve and sometimes cause miscommunication and miss coordination among fellow employees. In addition there are some civilians that its performance is less optimal, among others, the lack of use of time in the completion of tasks, such as in the office for no apparent reason, leaving the working hours, casual, indiscipline, many hours of work are not effected and lack of self-development/increase knowledge. These symptoms can be allegedly impact to reduce working performance and signaling low employee morale.

In looking at the general condition of civil servants who are assigned to the Indonesian Navy conveyed the problems in the development of career in real conditions, those are:

a. Civil Servant and military personnels who are serving in the Indonesian Navy are a unity, integrated together and responsible for the implementation of basic tasks navy. The use of civil servants in the navy made upon consideration their position in the navy are more effective and efficient held by civil servants because of the nature of the assignment which is generally in the field of non-combat relatively stationary. The purpose of civilian development in the navy is to realize the civil servants who have full of loyalty and obedience to the Pancasila and the 1945 Constitution, united, mentally well, disciplined, honest, clean and dignified, efficient and effective, high quality, and aware of its responsibilities as a state civil apparatus so it can be achieve the optimum performance and play role in the organization, it should be consistent with such tasks as mandated by the Decree of the TNI Commander No. Kep/19/V/2005 dated April 20, 2005 on basic instructions on personnel and human power of Indonesian National Armed Forces. 
b. Based on regulation of TNI Commander Number Perpang/28/X/2007 dated October 3, 2007, in the appendix, it is stated that the civil servant TNI is the complement of soldiers, therefore the civil service TNI and TNI soldiers is a unity that is integrated and responsible in the implementation of the main tasks of the military, where the integration should be reflected in all levels of the organization and each shall understand their role.

c. The purpose of the use of civil servant in the military organization is to gain efficiency and effectiveness in order to utilize a relatively long time by providing opportunities for achievement of every civil servant.

d. Thus, the development patterns should be formulated integratedly and comprehensive so that the career of civil servant can be developedasr high as possible and compete to occupy good positions in the ministry of defense and in the ranks of the military. So with the pattern set and proper implementation are expected to provide job satisfaction to every individual civil servants especially in the navy.

e. Navy civilian in overlooking at the environmental change strategy of the organization, is required to improve competencies include knowledge, skill and attitude, so as to contribute significantly in realizing the main tasks of the navy as a defense force at sea, as well as being part of the human resources naval defense that helped determine the role of the future.

f. Quantitatively, it can be concluded that the overall amount of strength of navy civiliansare still lacking, which is only about $34 \%$ of the amount are corresponding to the space class/rank. g. Given the imbalance between the numbers of existing positions with a number of civil servants, especially space class III, the number of civil servants were given the post of military expediency. However, the problem that arises is the duplication of personnel (civil and military) in one position, with the consequence of civil servants should be removed from his position, so that it causes discrapancy and lowering the morale of civil servants.

h. Qualitatively in general, it can be said that navy civilian have been carrying out its roles and functions in supporting of the main tasks of the navy, although it is still considered less than optimal even the current trend navy civilians have no longer act as a complement but rather as a supplement or substitution of soldiers, where positions are in DSP- its military can only be occupied by civil servants during unpresence of military personnel there or in other words only as a temporary replacement, and some of them should occupy the positions with lower job of rank. Relatively very little or even no civil servants were placed in positions that get a portion as an element of decision-makers, but only as an executive element routine.

i. Qualitatively, based on the readiness and motivation of civil servants to improve self-actualization (knowledge, skills, creativity, innovation, personality, leadership) is still lacking, so charging on the space class IV have not been met because the civil servants who have the ability to match qualification standards required by the job is very less. This is due, among others;

1) Stuck in the organizational culture that is not conducive (routine and tend to wait for orders).

2) Regular promotions that are not influenced by education and occupation particularly moved class II to III which have lacks of ability. So consequently the space class III is already excessive. 


\section{MInstitute ${ }_{\text {Int }}^{\text {Macrothink }}$}

International Journal of Human Resource Studies

ISSN 2162-3058

2017, Vol. 7, No. 4

j. In real terms it can be said that civil servants generally have no longer play a role as a complement but rather as a supplement or substitute for soldiers, it can be seen, among others:

1) Civil servants who have a high competitive level quite a few are frustrated/lost pride to the institution thus increasing the number of civil servants abundant/shifting cultivation.

2) Military positions occupied by civilian are only temporary measures, may be revoked at any time if the military will fill it, even though it has been confirmed by resolve letter of head of staff, and should be lower than rank.

3) Relatively very little or even no civil servants who are placed in positions that get a portion as an element of decision-makers, but only as an executive element routine.

4) Issues of justice (equity), particularly the treatment and recognition of the navy civilian disciplinary issues relating to the treatment of civil servants ethics has less attention on levellering.

k. Mean time between placement positions are longer than military personel. In fact there are some civil servants acknowledged to have the performance that can be seeded and have a high responsibility for his work, and able to contribute fully supports the smooth execution of the task unit or work unit, in this case the ability and expertise are formed generally for long time assignment of the working units (not prone to mutation). Especially the assignment of civil servants who are outside Java where military personnel within a certain time frame mutated.

\subsection{Expected Condition of Navy Civilian}

After analyzing, evaluating and changes to existing policies, it is expected the following changes:

a. There will be a balance between the level of quantitative (real number) and qualitative (education, skills, leadership, managerial) that everyone must have the appropriate personnel demands of tasks and functions that aspires, through:

1) Empowering navy civilians who have potential for filling vacancies for the post of space class IV to be fulfilled in accordance with DSP.

2) Their widest opportunity to navy civilians to participate in education and courses in bond.

3) On the implementation of procurement/recruitment of navy civilian in every unit of the navy outside of Java Island, in trying to fulfill the local personnel where the unit is domiciled, in order to empower the potential of the area without reducing the quality standards expected of personnel.

b. The use of the navy civiliansare expected to provide increased capacity to the its personnel optimally and able to enhance the work ethic/cultural work, productive behavior and confidence, noting that:

1) Navy civilian are expected to have excellence and high competitiveness based on competence and professionalism, so as to realize the PNS as a complement of soldiers in the realization of the main tasks of the navy.

2) Personnel Development (Binpers) and Career Development (Binkar) Navy Civilians are expected to be done in an objective, transparent and efficient, "the right man on the right job".

3) The performance assessment is expected to be conducted objectively, in order to raise the spirit of fair competition. 
4) Navy civilians who move class II to class III officer level are expected to have managerial capability (function manager) and leadership skills (function leader).

5) Navy civilians need attention, recognition and fair treatment based on the norms of equality (levellering) are already set, and not the treatment is based on the dichotomy of the military and civil servants.

\subsection{Analysis of the Problem}

To understand the existing problems, namely how efforts to empower the role and function of navy civilians in order to meet the expectations and demands as a naval resource with competitiveness in the future, it is necessary to discuss or analyze the current conditions, as follows :

a. In quantitative and qualitative navy civilian shows same direction comparattion, namely in quantity and less quality, but judging by the comparison of distribution with the demands of quality shows inversely, where the number of the power of group III (class III/b and III/a) the excess, but the quality is relatively poor. It is caused by several things, such as:

1) Regular promotion from class II (Senior High School) to group III, with Service Examination are less selective.

2) Procurement is less considered carefully as demanded maps available positions, and tend to pursue the quota of the quality.

3) Low level / number of civilian who retire until 2018.

4) Possible reception quality standards of navy civilian is lower than the general standard and the selection process is less stringent.

5) The high degree of official intervention in the process of recruitment and selection of navy civilian.

6) Less function of Personnel Development function Command (BFK/Binpers Fungsi Komando) by the project implementing unit heads to navy civilian, and less objective in their assessments.

b. Less optimal use of navy civilian role and function as a complement, due to several reasons:

1) The imbalance between the amounts of power of civil servants are there with DSP, especially in group III (First Officer level).

2) A lack of enthusiasm and willingness of navy civilian to learn and develop themselves according to the demands professionalism.

3) Work ethic is lacking, because of the tendency of civil servants navy prioritize the interests of the official family (unprofessional). This is due to the fact that the income received is minimal compared to the demands of existing needs, so they still tend to think of how to make ends meet.

4) There are still many positions that are possible can be occupied by civil servants but has not been given the trust and the opportunity to navy civilian.

5) The lack of healthy competition and objectively in the navy civilian because of the lack of selection in education development. During this time based solely on who would and did not consider whether the relevant capabilities can be developed either managerial and leadership. 
6) An organizational culture that puts navy civilian only as suplement attitudes have formed their behavior does not develop, passive and insecure.

c. Working relationships between members of the military tend dichotomous with navy civilian causes less participative and less productive work ethic, because it always feels himself less capable and less needed.

d. Navy civilian who have the expertise, capability and loyalty that facilitate the task of the organization, given less attention has not even embodied in existing job.

\subsection{Efforts of Problem Solving}

To solve the problems and answer the challenges ahead is how to build navy civilian as a truly military complement, need necessary efforts significantly and synergy between, leadership, the environment and the navy civilian itself. These efforts include:

a. The necessity of carrying out the counting and mapping back in quantity that is to be aligned with a map of existing positions, and establish a policy on setting recruitment and implementation of selection is strictly based on competencies (quality) in the procurement of navy civilian, upto the ideal condition of the power of navy civilian.

b. Strictly carry out the selection candidates in each screening level education (Diklatpim) to measure the level of both managerial and leadership ability and motivation of navy civilian to develop.

c. Service examination as a means of filtering moving space class, the navy civilian of class II (equivalent NCO) to space class III (equivalent officer), should be done selectively and tightly, not only with a written test that has been structured, but the need for other tests for measure their general competence (knowledge, skills, and attitudes/behaviors) such as interview involving user unit to give consideration.

d. Creating a conducive working environment, in this case the need for perception in developing human resources both civil and military, in order that each aware that they are in a relationship role as a supplier in the implementation of the main tasks of the navy, to support the creation of a working relationship healthy and happy and the high spirit of working together, thus increasing the work ethic and job satisfaction for all parties.

e. Provides opportunities for navy civilian to develop themselves through education, training and courses selectively.

f. Implement career development clearly and provide development opportunities for navy civilian's potential and professional at all positions that are non-combattan, such as the positions that are the techniques, positions in health and occupation in the field of administrative considerations positions of the more efficiently and effectively occupied by civil servants because the rate of movement of their relatively low, so that with the passage of years of service, they will become civil servants experts in the field and become an asset for the navy.

g. The necessity to set the policy enrichment positions (job enrichment), which is an effort to create jobs with the challenge, responsibility and greater autonomy allowing the PNS navy would have more appeal, to be more responsible, achievement and will produce output more quality. 
h. Strengthening the culture of the organization. Strong organizational culture provides a clear understanding of the tasks given by the organization, has a great influence on the behavior of its members because of the high level of togetherness. Cultural organizations can also foster cohesiveness, loyalty and commitment. With the strong organizational culture and healthy in the organization the navy will have a positive impact for the organization. Strong and healthy organizational culture can be used as a binding requirement for employees formally formulated into various regulations. If the navy personnel are awarded an understanding of the organizational culture so any personnel of the navy will be motivated and passion to perform any tasks given by the organization. It is one of the keys to obtain optimal performance to achieve organizational goals.

\section{Conclusion and Suggestion}

\subsection{Conclusion}

From the description above can be concluded that in order to empower the function and role of navy civilian and answering the problems that exist, are as follows:

a. Empowerment of the role and function of navy civilian is a complex issue and must be viewed from multiple angles.

b. Role and function conditions of navy civilians today as a complementare not optimal. The condition is influenced by several things such as recruiting less in accordance with quality standards, the amount of force that is not ideal, organizational culture, environment less conducive and so forth.

c. Their changing demands of the role and function of navy civilian, requires the support of leadership in terms of establishing the policies of both the tangible (managing institutional structure, DSP/TOP, providing infrastructures needed) and the intangible (develop norms, ethics and the organization's internal procedures), which can improve the work ethic/cultural work and good behavior of both navy civilian and military.

d. Creating an open and healthy competition in the development of educational and career of navy civilian as much as possible, so that it will awaken comparisons between the roles and functions in the same direction with the development of career civil servants in the organization of the navy.

\subsection{Suggestion}

For implementation effectiveness on the empowerment of the role and functions of navy civilian in order to answer the problems that exist today, it can convey the following suggestions:

a. Need a common perception and commitment of all parties at all levels of the navy management, to understand and respond to the demands of the role and functions of the navy civilian forward.

b. The need for a comprehensive evaluation of the role and function of navy civilian today and rearrange map positions correspond to the career patterns of the navy civilian that have been defined. 
c. There needs to be a clear distinction between the positions in the structure of military posts (barrier function) and civilian (administrative functions) on a job level balanced with regard to job analysis of each position.

d. Provide career opportunities more with set policies enrichment positions for navy civilian, in this case becomes one of the alternatives to establish the post of officer navy civilian development as a positions that are functionally handling the development of civilian and providing opportunities for career development of navy civilian.

e. Personnel Development Command Function (BFK) should also be implemented optimally to navy civilian by the project implementing unit heads and the function of project implementing unit heads is as an objective evaluator in the process of career development of navy civilian.

\section{References}

Brad, M., Peter, M., \& Harsha, P. N. (2017). School of Teaching \& early Childhood, University of Southern Queensland, Toowoomba, Australia. "Pre-service Teachers' Self-Efficacy Mediates the Relationship between Career Adaptability and Career Optimism". Elsevier Ltd. All rights reserved.

Decree of the Chief of Naval Staff Skep No./933/VI/2006 dated June 28, 2006 Pattern Career, Placement and Position of Civil Servants Navy.

Edgar, H. S. (2015). MIT Sloan School of Management Cambridge MA, USA. (C) 2015. "Corporate Culture". Elsevier Ltd. All rights reserved.

Gary, D. (2015). Human Resources Management. Jakarta: Four Salemba.

Government Regulation No. 46 Year 2011 dated December 1, 2011 on Job Performance Assessment of Civil Servants.

Government Regulation of the Republic of Indonesia Number 100 of 2000, as amended by the Government Regulation of the Republic of Indonesia Number 13 Year 2002 concerning the appointment of civil servants in structural positions.

Head of State Employment Agency Regulations No. 1 of 2013 dated January 3, 2013 on the Implementation of the Provisions of Government Regulation No. 46 Year 2011 on Job Performance Assessment of Civil Servants.

Law of the Republic of Indonesia Number 43 of 1999 on Principles of Civil Service.

Law of the Republic of Indonesia Number 5 year of 2014 concerning the State Civil Apparatus.

Michael, Q. P. (2016). Qualitative evaluation methods. Yogyakarta: Student Library.

Nusa, P., \& Hendarman. (2012). Policy Research Methodology. Bandung: PT. Teens Rosda Karya.

Peraturan Panglima TNI. No. /161/ XII / 2011 dated December 6, 2011 on Guidelines Personnel Development Administration of Civil Servants.

Peter, A. C., Michelle, H., \& Shi, H. S. (2016). Of Applied Psychology and Menzies Health Institute Queensland Australia. "Personal Orientation Career As An antecedent To Stress and Employability Confidence: The Roles of Intervening Career Goal-Performance Discrepancy 


\section{Macrothink}

and Career Goal Importance".

Presidential Regulation No. 80 of 2011 Concerning the Grand Design Reforms Indonesia from 2010 to 2025 .

Riant, N. (2016). Policy Research Methods. Yogyakarta: Student Library.

Victor, D. (2010). The Leadership and Ethics Center. Northern Ireland. "Ethics and the Military Community". Journal of Defense Research Management, 1(1), 69-76.

Wirawan. (2016). Theory of Evaluation Model, Methodology, Standards, Applications and Professional. Jakarta: PT.Raja Grafindo Persada.

Yoram, K., Xi, G., \& Theodor, F. (2016). University of Michigan, Ann Arbor, MI, USA. "The Impact of Corporate Culture on manufacturing system design". Elsevier Ltd. All rights reserved.

\section{Copyright Disclaimer}

Copyright for this article is retained by the author(s), with first publication rights granted to the journal.

This is an open-access article distributed under the terms and conditions of the Creative Commons Attribution license (http://creativecommons.org/licenses/by/4.0/). 